\title{
Assessing Business-IT Alignment Maturity at a Colombian University
}

\author{
Miguel Eduardo Torres-Moreno, Pontificia Universidad Javeriana and Universidad Nacional de Colombia, Facultad de \\ Ingeniería,, Bogotá, Colombia \\ iD https://orcid.org/0000-0002-5011-7595
}

Jairo Hernán Aponte-Melo, Universidad Nacional de Colombia, Facultad de Ingeniería, Bogotá, Colombia

\begin{abstract}
Over the last decades, the role of the IT department within an organization has gradually gained importance. Technology has permeated all areas within organizations and nowadays is the cornerstone of almost all business processes. Thus, business-IT alignment (BITA) is considered an essential success factor for almost any organization. Consequently, the evaluation and improvement of this alignment have been growing concerns among researchers and organizations. This study assessed the BITA maturity in a Colombian university, applying Luftman's SAM (strategic alignment maturity) model. The conducted assessment collected, analyzed, and contrasted perceptions of business and IT personnel. Similarly, the authors investigated the personnel's perceptions at the strategic, functional, and operational levels regarding the SAM factors. Furthermore, they compared the results with other BITA assessments in educational institutions, Latin American organizations, and worldwide results. Finally, they drew some conclusions that can be useful for practitioners who seek to apply Luftman's assessment.
\end{abstract}

\section{KEYWORDS}

Business-IT Alignment, IT Governance, Strategic Alignment, Strategic Alignment Model

\section{INTRODUCTION}

As (Chan \& Reich, 2007) highlight, the strategic Business/Information Technology Alignment (BITA) has been a recurring research topic for the past thirty years, mainly due to the strong impact of information technology (IT) investment in hardware/software and its long-term effects on the organizations' performance. In that sense, (Luftman, 2000) states that the alignment should focus on how IT and business achieve mutual or bidirectional harmony. Over time, alignment should evolve to a state in which both strategies, i.e., business and IT, advance together, requiring management activities specifically aimed at achieving cohesive goals across all the organization units.

In the early 90s, (Henderson \& Venkatraman, 1993) developed a pivotal model, namely the Strategic Alignment Model (SAM). They conceptualized the domains of strategic alignment and the interrelationships among them, which allowed researchers to formulate modern Business/IT Alignment theories. In parallel, researchers have created approaches for measuring alignment and assessing alignment maturity levels within organizations. In turn, these levels form the conceptual basis 
that allows organizations to define and implement processes of alignment adjustment and alignment enhancement. Thus, before implementing specific actions to improve the IT alignment with business goals, instruments that allow organizations to assess their alignment maturity are required. Such measuring tools are crucial to continuously monitor the effectiveness of the management programs and actions implemented to improve alignment and guide long-term strategies that keep business and IT aligned.

One of these instruments, designed by Luftman (J. Luftman et al., 2017), identifies the fundamental dimensions that foster BITA and defines a method that aims to assess BITA maturity level in an organization. This method allows the organization to determine its BITA level on a scale of five maturity levels. Additionally, it helps the organization recognize and understand its alignment reality, identify weaknesses and strengths in its operation, and support plans that leverage opportunities to enhance the relationships between business and IT. It is worth mentioning that the statistical validation of the instrument as presented by Luftman (J. Luftman et al., 2017) shows the relationship between the various dimensions of alignment and the firm performance and assesses the impact of alignment on it.

The rest of this paper is organized as follows. First, in the LITERATURE REVIEW section we summarize the key definitions, fundamental concepts and most relevant BITA research. After that, in the METHODS section, we explain the instrument and describe how it was used to assess BITA in the selected organization. Then, in the CHARACTERIZATION OF THE ORGANIZATION section, we describe the organization under study, its organizational structure, the interviewees, and how the instrument was applied. Next, in the ANALYZING THE RESULTS section, we present the study results. Then, in the DISCUSSION section, we discuss our main findings and compare them against those reported by Luftman. Finally, we draw some conclusions regarding Luftman's model application and propose research areas that would complement this study.

\section{Problem Definition and Contribution}

The main problem we addressed in this study is the evaluation of BITA in a higher education organization. Assessing the current state of the alignment is a sound starting point for designing and implementing management strategies to improve BITA progressively. Moreover, the periodic measurement of alignment helps to evaluate the effectiveness of such strategies within the organization in the long run.

In this sense, this paper aims to present a practical case analysis, where we assessed the degree of BITA at a Colombian university by applying the Luftman instrument. Based on interviews and information collected when performing the evaluation process, we assessed and analyzed the organization's current state of alignment and provided reliable data to support its evolution and continuous improvement.

The contributions of this paper are as follows:

- We assessed the BITA maturity in a higher education institution with more than 30.000 students and more than 1.500 faculty members, applying Luftman's SAM model.

- We analyzed the differences between business and IT personnel's perceptions investigating the latter at the strategic, functional, and operational levels regarding all the SAM factors.

- Regarding similar studies, we first compared the results of this study with 11 similar studies in higher education institutions, reported by Luftman. Second, we contrasted our results with those of 44 Latin American organizations reported by Luftman. Lastly, we weigh these results against the overall results of 395 organizations.

- Lastly, we provide some insights and recommendations on how to apply Luftman's instrument within universities. 


\section{LITERATURE REVIEW}

This section presents a literature review, along with the concepts related to what it is and how strategic alignment is evaluated.

\section{Strategic and Business/IT Alignment (BITA)}

Strategic Alignment has been an active research area for the last thirty years, mainly due to the substantial impact of IT investment in hardware and software and its long-term effects on the organization's performance (Chan \& Reich, 2007). The most recent description of alignment, according to (J. Luftman et al., 2017), states that " strategic alignment focuses on the activities that management performs to achieve cohesive goals across the IT and other functional organizations (e.g., finance, marketing, H/R, manufacturing). Therefore, alignment addresses how IT is in harmony with the business, and how it should or could be in harmony with IT. Alignment evolves into a relationship where the function of IT and other business functions adapt their strategies together".

In perspective, alignment should cover all levels of an organization, i.e., strategic, operational, system, project, and even the personal/individual scope. In that sense, the work of (Henderson \& Venkatraman, 1993) is regarded as seminal in the area. It has been the basis of several approaches that aimed to conceptualize a Strategic Alignment Model (SAM). However, that model considers only the structural and strategic/intellectual dimensions, as defined by (Blaize Horner Reich \& Benbasat, 2000).

Recent research by (Zhang et al., 2018) proposes extending the SAM model to relate it to Enterprise Architecture (EA) planning. Specifically, they propose to separate IT from IS (Information Systems), thus creating a new element in the model, leaving IS as the middle column, and dividing the "functional" row into "enterprise planning" and "solution delivery" to separate the abstractions and models from their actual implementation. Another similar proposal is the one by Beffers et al. (Beffers \& de Waal, 2018), who build over the BiSL (Business Information Services Library) ("BiSL," n.d.) processes and recommendations to improve alignment when using BiSL. Héroux et al. (Héroux \& Fortin, 2018) perform an analysis describing how BITA can affect IT governance and its impact on organizations' innovation capabilities by assessing BITA using questionnaires. Based on what they call Resource-Based View (RBV), they argue that alignment can be observed only in relationships and not in patterns, because it is too difficult to trace and comprehend. The same viewpoint was argued by (Majstorović, 2016; Park et al., 2017), (Majstorović, 2016).

Several efforts have emerged into the operationalization of BITA at various levels; Goni et al. (Goni et al., 2017) present a study into how IS alignment can affect higher education institutions in Malaysia and, in particular, their efforts on sustainability, organizational agility, and risk management. Street et al. (Street et al., 2017) studied strategic alignment for small and medium enterprises (SMEs) context and proposed recommendations to achieve alignment within SMEs. Another exciting evolution on BITA is Vasconcellos et al. (Vasconcellos et al., 2017) proposal, which seeks to ensure alignment when a company aims to develop its Software Process Improvement capacity (SPI) and ensure its alignment with the business. Also, concerning how BITA can be used and operationalized (Oehlhorn et al., 2020) studied the impact of BITA on the organization's human resources function. In the same context (Buchalcevova \& Pour, 2018) presented the Management of Business Informatics model, which aims to provide support for management Information and ICT activities within a company using alignment as the guiding force of the proposed processes. Ilmudeen (Ilmudeen et al., 2019) studied the relationship between alignment and performance and related them using organizational performance measures. Wautelet (Wautelet, 2019) proposes a requirements-based approach to model and connect business and IT strategic goals into system definitions using $\mathrm{i}^{*}$ as a modeling language to evaluate business and IT services' alignment to the strategic objectives.

In the context of education, the type of organization we evaluated, it is worth highlighting the work carried out by the Conference of Rectors of Spanish Universities (CRUE), (Fernández Martínez \& Llorens Largo, 2011). This work is based on ISO 38500 (Calder, 2019) and COBIT (ISACA, 2018), 
and describes the GTI4U model (Governance of IT for Universities), a specific IT governance model for universities. The premises were that universities' problems and their corporate and IT governance are particular to this enterprise, highlighting that universities are non-profit organizations. The expected earned value would not always be based on financial terms but with greater relevance on qualitative elements such as intangible benefits (social impact, reputation, goodwill, etc.). Thus, this document presents a tool for performing a self-assessment of the state of maturity of the IT governance and BITA (Gti4u, n.d.). Finally, Putz et al. (Putz et al., 2017) is a similar work that presents a method to assess strategic alignment in Brazilian federal universities based on a short questionnaire and Likert scales.

\section{Assessing Alignment}

As already mentioned, for achieving and managing alignment, it is vital to measure and evaluate it. One of the first and most cited approaches to assess strategic alignment was reported by (Blaize Homer Reich \& Benbasat, 1996). They proposed to evaluate alignment in two dimensions: intellectual/ structural and social. Later, other approaches appeared, mostly based on Venkatraman and Henderson's SAM, which mainly describes the intellectual/structural dimension.

Enterprise architecture (EA) 's main focus is to support alignment through structural means, i.e., relating business with IT, through models and abstractions (Gampfer et al., 2018). In this regard, ElMekawy et al. present a method to assess BITA using a set of metrics traced to EA structures (Elhari \& Bounabat, 2011; El-Mekawy et al., 2015). Another method uses Balanced Scorecard (BSC) as the primary tool to measure and assess alignment (Huang \& Qing Hu, 2007), while other authors mention a method based on a knowledge-based view for assessing alignment (Kearns \& Sabherwal, 2006).

Lastly, the most influential researcher in this field is Jerry N. Luftman (J. Luftman et al., 2017). Luftman's primary research shows how alignment significantly affects the firm's performance and supports efficiency on the firm's business process management (BPM) strategy as well (Brocke \& Rosemann (eds.), 2015). From his seminal studies (J. Luftman, 2000; J. N. Luftman, 1996, 2003) and their updated version (J. Luftman et al., 2017), Luftman proposes a method that aims to assess BITA maturity in an organization based on Henderson and Venkatraman's SAM and its components.

Luftman's approach was first tested in 1996 and, since then, it has been updated regularly, with the latest update in 2017. There have been more than 3000 respondents and interviewees, covering around 395 global "Fortune 100" companies worldwide, involving a wide range of industries, including retailing, hotel, insurance, oil/gas/mining, financial, utility, education, among others.

Other authors report using Luftman's instrument, for instance, to assess and identify the impact of IT governance implementations on BITA (De Haes \& Van Grembergen, 2009). Furthermore, in Latin America (Gutierrez et al., 2008, 2009) and Russia (T.S, 2017) describe efforts to assess several industrial sectors' alignment by collecting data from individuals in SMEs. However, the authors of these previous examples report that only a couple of people answered Luftman's questionnaire for each company, and it was not necessarily applied as an interview. This circumstance involves the risk of leaving the survey questions to the free interpretation of the interviewee.

Another exciting direction of research in managerial sciences is proposed by (Haghighi Rad \& Rowzan, 2018), which present a model for evaluating the IT portfolio to assess its degree of alignment. In the same area (Baker \& Singh, 2019) propose a model based on system dynamics, seeking to identify processes and people within the organization to achieve alignment instead of the factors presented by Luftman and Henderson / Venkatraman.

Business Application Strategic Alignment Model (BASAM) (Berberat \& Baudet, 2019) is an evaluation model for Information Systems. The model assesses the degree of alignment with the business of any given IS, giving IT managers a chance to evaluate the value that any IS provides to the business concerning the strategies of both business and IT, the organizational structure, and the business and IT operations. In the same line of work (Darii et al., 2020) propose a set of metrics derived from the Henderson and Venkatraman model, also using the six dimensions used by Luftman 
in his instrument to measure SI efficiency and an evaluation of the degree of alignment of the IS with the business.

\section{METHODOLOGY}

This section describes the Luftman approach, the particular method we applied for performing the assessment. Luftman's strategic alignment maturity (SAM) method assesses alignment maturity in a typical five-level scale. Specifically, the levels are: (1) Initial/Ad Hoc Process, (2) Committed Process, (3) Established Focused Process, (4) Improved/Managed process, and (5) Optimized Process (J. Luftman et al., 2017). The model allows an organization to identify weaknesses and strengths in its operation, using a questionnaire where each factor is evaluated using a Likert scale from 1 to 5 , plus a sixth option used to indicate that the interviewee does not know, or that the question does not apply. The model uses six different perspectives or views (Communications, IT and Business Value Metrics, IT Governance, Partnership / Associations, IT Scope and Infrastructure, and Human Resources/Skills) to group the different factors and evaluates thirty-nine factors/questions in total.

Each dimension covers a subset of questions and is described as follows (J. Luftman et al., 2017):

- Communications measure IT and Business effectiveness in exchanging ideas, knowledge, and information and understanding their strategies, plans, risks, and priorities.

- IT Competence and Value address the level of metrics used to show IT contributions to business to both use and comprehend them.

- IT Governance evaluates IT strategic decisions and how IT and business define their priorities and allocate IT resources.

- Partnership/association measures how working relationships are maintained between the business and IT, the degree of trust, and their perception of each other.

- IT scope and infrastructure determine the perception level of IT infrastructure use of technologies and the activities that allow business processes to change and deliver solutions to business units.

- IT skills evaluate human resources activities (hiring, retention, training, performance evaluation) and how innovation, skill development, and career opportunities are laid out for employees.

In this study, the questionnaires used are the ones published by Lufman in 2017 (J. Luftman et al., 2017). The questionaries were applied to IT and business executives in the form of an interview. Their answers were tabulated, and various measures were calculated (e.g., average, standard deviation) for each factor and then for each dimension. After each dimension was assessed, the resulting value was reported along with the generic recommendations proposed by Lufman (J. Luftman, 2000). The interviews' detail gives rise to the opportunity to deepen and formalize specific recommendations for the organization.

To improve the analysis, Luftman proposes that the results should be separated according to the interviewed groups, i.e., IT and Business, to compare the results. The organization can then decide which initiatives or changes perform to improve any dimension or factor.

\section{CHARACTERIZATION OF THE ORGANIZATION}

The university where this study took place is Pontificia Universidad Javeriana, in Bogotá, Colombia. The university has two campuses that operate autonomously: the campus in Bogotá, the country's capital city, and a branch in Cali, which is the third-largest city of Colombia. For this study, only the information of interviewees at the Bogotá campus was taken into account. 
Table 1. Distribution by type of functional unit

\begin{tabular}{|c|c|c|}
\hline Type & Quantity & Percentage \\
\hline BUS & 35 & $74 \%$ \\
\hline$I T$ & 12 & $26 \%$ \\
\hline Total & $\mathbf{4 7}$ & $\mathbf{1 0 0 \%}$ \\
\hline
\end{tabular}

\section{The University Structure}

The organizational structure of the university is composed in the top level of the General Government, with the following positions (Estructura Organizacional I Pontificia Universidad Javeriana, n.d.):

- The University Board of Directors

- The Presidency of the University

- The General Secretary

- The Planning Secretary

- The Academic Council

- The Administrative Council

- The University Wellbeing Council

- The Academic, Research, Administrative, International Affairs, and Wellbeing Vice-chancellors

At the school level, the management positions are as follows:

- The School Council

- The Academic Dean

- The Dean of the University Environment

- The School Secretary

- The Directors of departments, institutes, and undergraduate, specialization, master, and Ph.D. programs.

By 2016, the campus in Bogotá had more than 1,500 administrative employees, 1.200 faculty members, and more than 24.000 graduate and undergraduate students (Índice $::$ BOLETÍN ESTADÍSTICO 2016, n.d.).

\section{The Interviewees}

Sixty-two (62) people from the Bogotá campus were invited by email to participate in the study. We made sure that they were involved in the decision-making process in the different functional areas of the organization. Forty-seven (47) of them accepted our invitation and took the survey. Only one person responded to the survey using an online version, while the remaining forty-six (46) were interviewed face-to-face in sessions lasting between 1 and 1.5 hours. The interviews were conducted between March and August 2018.

For analysis purposes, Luftman's instrument separates the interviewees into two groups: Business staff and Information Technology staff. Our Business staff group (BUS) had 35 interviewees, while the people associated with the Information Technology (IT) area were 12. This second group belongs to the DTI - Information Technology Directorate, which is part of the Administrative Vice Rectory (See Table 1).

Respondents were classified according to their level of participation and responsibilities in strategic management within units. The first area is strategic (EST), that is, people in managerial 
Table 2. Distribution by hierarchical position in the functional unit

\begin{tabular}{|c|c|c|}
\hline Hierarchy & Quantity & Percentage \\
\hline$E S T$ & 24 & $51 \%$ \\
\hline FUN & 13 & $28 \%$ \\
\hline OP & 10 & $21 \%$ \\
\hline Total & $\mathbf{4 7}$ & $\mathbf{1 0 0 \%}$ \\
\hline
\end{tabular}

positions within the unit that take strategic decisions. The second area is functional (FUN) and comprises people responsible for the execution of the operation and monitoring of strategic decisions of the unit, and with little intervention in the decision making process within the unit. The third area is operational (OP), where people execute and respond vis-à-vis to the functional area in terms of day-to-day operations, and are generally not involved in making strategic decisions. Table 2 shows the distribution by hierarchical position in the functional unit, and Table 3 the distribution of the interviewees' roles in the university's functional areas.

Each personal interview was performed as follows. First, the interviewer explains the survey context; then, the interviewee briefly describes his/her role and responsibilities; lastly, the interviewer performs the interview following Luftman's instrument (J. Luftman et al., 2017). The interviewer obtains each response, records the rationale behind it, and performs complementary questions to understand better the organization and the answer given by the interviewee. Each interview was recorded and later transcribed and used in the qualitative analysis of the study. Thirty-eight (38) interviews were transcribed for later analysis, emphasizing the answers given by the staff of the Administrative Vice-Rectory and the DTI. The remaining nine (9) interviews were not transcribed because they provided no relevant or new information that contributes to the study.

\section{ANALYZING THE RESULTS}

This section presents the results of the study. For each dimension, quantitative data is organized as follows. First, a table compares data obtained in the business group (BUS) with data from the IT area. Another table contrasts the results obtained in the three groups: Strategic / Functional / Operational levels. In both tables, the column number corresponds to the question number within the dimension. The first two rows of each area correspond to the average (Ave. (w / o 6)) response without option 6

Table 3. Distribution of interviewees

\begin{tabular}{|l|c|c|c|c|c|}
\hline \multicolumn{1}{|c|}{ Functional Area } & $\begin{array}{c}\text { Strategic } \\
\text { Level }\end{array}$ & $\begin{array}{c}\text { Functional } \\
\text { Level }\end{array}$ & $\begin{array}{c}\text { Operative } \\
\text { Level }\end{array}$ & Percentage & Total \\
\hline General Secretary & 3 & - & - & $6 \%$ & 3 \\
\hline Planning Secretary & 1 & 1 & 1 & $6 \%$ & 3 \\
\hline Administrative Vice-Rectory & 6 & 5 & 6 & $36 \%$ & 17 \\
\hline International Rel. Vice- Rectory & 5 & - & - & $11 \%$ & 5 \\
\hline Academic Vice-Rectory & 3 & 6 & 3 & $26 \%$ & 12 \\
\hline Wellbeing Vice-Rectory & 4 & - & - & $9 \%$ & 4 \\
\hline Research Vice-Rectory & 2 & 1 & - & $6 \%$ & 3 \\
\hline Total & $\mathbf{2 4}$ & $\mathbf{1 3}$ & $\mathbf{1 0}$ & $\mathbf{1 0 0} \%$ & $\mathbf{4 7}$ \\
\hline
\end{tabular}


Table 4. Communications - Business vs. IT

\begin{tabular}{|c|c|c|c|c|c|c|c|}
\hline & Question & 1 & 2 & 3 & 4 & 5 & 6 \\
\hline \multirow[t]{3}{*}{ BUS } & Ave. (w/o 6) & 3,23 & 2,66 & 3,11 & 3,51 & 3,35 & 3,06 \\
\hline & Std. Dev (w/o 6) & 0,84 & 0,87 & 0,93 & 0,89 & 1,35 & 1,35 \\
\hline & \multicolumn{7}{|l|}{$\begin{array}{l}\text { Average: } 3,15 \\
\text { Std. Dev: } 0,29\end{array}$} \\
\hline \multirow[t]{3}{*}{ IT } & Ave. (w/o 6) & 2,83 & 2,33 & 2,33 & 3,92 & 2,50 & 3,00 \\
\hline & Std. Dev (w/o 6) & 0,58 & 0,65 & 0,78 & 0,52 & 0,67 & 0,85 \\
\hline & \multicolumn{7}{|l|}{$\begin{array}{l}\text { Level (Average): 2,82 } \\
\text { Std. Dev: } 0,60\end{array}$} \\
\hline
\end{tabular}

and the standard deviation (Std. Dev (w / o 6)) without option 6. The last row has the Average and the Standard deviation of the calculated level of the questions averages (See Table 4 and Table 5). Finally, another table shows and compares all participants' collected data (See Table 6).

\section{Communications}

Table 4 consolidates the evaluation of the business area respondents (BUS) compared with those of Information Technology (IT).

Table 5 shows the results of the evaluation given by the respondents who are in Strategic positions (EST) along with those of the Functional (FUN) and Operational (OP) roles.

Finally, Table 6 shows the results of the evaluation by the entire population. The top six rows have the percentages of respondents who answered the corresponding column number.

There is a consensus among interviewees that the understanding and knowledge exchange between the business and IT areas are being reached, at least at the senior and middle management levels. Moreover, IT has a stronger relationship with the Academic and Administrative vice-rectories and a forming bond with the Wellbeing vice-rectory.

On the other hand, organizational learning is perceived as structured with systematic and transparent methods. For many interviewees, making a more detailed follow-up/evaluation of

Table 5. Communications - Strategic (EST) vs. Functional (FUN) vs. Operative (OP)

\begin{tabular}{|c|c|c|c|c|c|c|c|}
\hline & Question & 1 & 2 & 3 & 4 & 5 & 6 \\
\hline \multirow[t]{3}{*}{ EST } & Ave. (w/o 6) & 3,46 & 2,71 & 3,21 & 3,71 & 3,67 & 3,29 \\
\hline & Std. Dev (w/o 6) & 0,83 & 0,91 & 0,98 & 0,75 & 1,13 & 1,16 \\
\hline & \multicolumn{7}{|l|}{$\begin{array}{l}\text { Level (Average): } \mathbf{3 , 3 4} \\
\text { Std. Dev: } \mathbf{0 , 3 7}\end{array}$} \\
\hline \multirow[t]{3}{*}{ FUN } & Ave. (w/o 6) & 2,69 & 2,08 & 2,62 & 3,39 & 2,31 & 2,54 \\
\hline & StdDev (w/o 6) & 0,48 & 0,28 & 0,77 & 1,04 & 1,18 & 1,45 \\
\hline & \multicolumn{7}{|l|}{$\begin{array}{l}\text { Level (Average): } 2,60 \\
\text { Std. Dev: } 0,44\end{array}$} \\
\hline \multirow[t]{3}{*}{ OP } & Ave. (w/o 6) & 2,80 & 2,70 & 2,40 & 3,60 & 2,78 & 3,00 \\
\hline & StdDev (w/o 6) & 0,63 & 0,82 & 0,84 & 0,69 & 0,97 & 0,87 \\
\hline & \multicolumn{7}{|l|}{$\begin{array}{l}\text { Level (Average): } \mathbf{2 , 8 8} \\
\text { Std. Dev: } 0,40\end{array}$} \\
\hline
\end{tabular}


Table 6. Communications - Total

\begin{tabular}{|c|c|c|c|c|c|cc|}
\hline Question & $\mathbf{1}$ & $\mathbf{2}$ & $\mathbf{3}$ & $\mathbf{4}$ & $\mathbf{5}$ & $\mathbf{6}$ \\
\hline 1 & $0 \%$ & $2 \%$ & $2 \%$ & $4 \%$ & $6 \%$ & $15 \%$ \\
\hline 2 & $21 \%$ & $55 \%$ & $34 \%$ & $4 \%$ & $30 \%$ & $13 \%$ \\
\hline 3 & $49 \%$ & $28 \%$ & $43 \%$ & $21 \%$ & $28 \%$ & $36 \%$ \\
\hline 4 & $26 \%$ & $13 \%$ & $13 \%$ & $66 \%$ & $13 \%$ & $21 \%$ \\
\hline 5 & $4 \%$ & $2 \%$ & $9 \%$ & $4 \%$ & $21 \%$ & $13 \%$ \\
\hline 6 & $0 \%$ & $0 \%$ & $0 \%$ & $0 \%$ & $2 \%$ & $2 \%$ \\
\hline Ave. (w/o 6) & 3,13 & 2,57 & 2,92 & 3,62 & 3,13 & 3,04 \\
\hline $\begin{array}{l}\text { Level (Average): 3,07 } \\
\text { Std. Dev: 0,34 (w/o 6) }\end{array}$ & 0,80 & 0,83 & 0,95 & 0,82 & 1,26 & 1,23 \\
\hline
\end{tabular}

organizational learning is required, especially for feedback and improvement. Furthermore, the definition of training plans for new positions is a constant need.

Regarding the communications protocol, all respondents agree that it is moderately formal and moderately flexible. Additionally, respondents in strategic positions indicate that this protocol also includes suppliers.

\section{IT Competence and Value}

Table 7 shows the evaluation given by the Group of Business (BUS) respondents, in comparison with those of Information Technology (IT).

Table 8 shows the evaluation given by interviewees in strategic positions (EST) opposed to those in the functional (FUN) and operational (OP) roles.

Finally, Table 9 shows the evaluation given by the entire population interviewed.

The use of IT and business metrics is typically based on ROI and, in most cases, on the definition of qualitative benefits, mainly due to the non-profit nature of the institution. Furthermore, we observed that IT and business value measurements begin to be related and formalized, although only at the strategic and planning levels, i.e., for projects with high financial impact and depending on the organizational unit.

Regarding the service level agreements (SLA), there is no single answer; it changes between the purely technical (e.g., service metrics) to the care and attention to the human side (e.g., quality

Table 7. IT competence and value - Business vs. IT

\begin{tabular}{|c|c|c|c|c|c|c|c|c|c|}
\hline & Question & 1 & 2 & 3 & 4 & 5 & 6 & 7 & 8 \\
\hline \multirow[t]{3}{*}{ BUS } & Ave. (w/o 6) & 2,20 & 3,06 & 3,15 & 3,09 & 3,56 & 3,60 & 2,73 & 4,03 \\
\hline & StdDev (w/o 6) & 1,19 & 1,13 & 0,80 & 0,90 & 1,02 & 1,16 & 1,14 & 0,97 \\
\hline & \multicolumn{9}{|l|}{$\begin{array}{l}\text { Level (Average): 3,18 } \\
\text { Std. Dev: 0,56 }\end{array}$} \\
\hline \multirow[t]{3}{*}{ IT } & Ave. (w/o 6) & 1,75 & 1,90 & 2,36 & 2,42 & 2,25 & 3,20 & 2,18 & 3,58 \\
\hline & StdDev (w/o 6) & 0,75 & 0,32 & 0,67 & 0,52 & 1,06 & 0,63 & 0,75 & 0,79 \\
\hline & \multicolumn{9}{|l|}{$\begin{array}{l}\text { Level (Average): } 2,46 \\
\text { Std. Dev: } 0,63\end{array}$} \\
\hline
\end{tabular}


Table 8. IT competence and value - Strategic (EST) vs. Functional (FUN) vs. Operative (OP)

\begin{tabular}{|c|c|c|c|c|c|c|c|c|c|}
\hline & Question & 1 & 2 & 3 & 4 & 5 & 6 & 7 & 8 \\
\hline \multirow[t]{3}{*}{ EST } & Ave. (w/o 6) & 2,39 & 2,91 & 3,30 & 3,22 & 3,63 & 3,70 & 2,79 & 4,00 \\
\hline & StdDev (w/o 6) & 1,24 & 1,08 & 0,82 & 0,90 & 1,01 & 1,26 & 1,25 & 1,06 \\
\hline & \multicolumn{9}{|c|}{$\begin{array}{l}\text { Level (Average): 3,24 } \\
\text { Std. Dev: } 0,53\end{array}$} \\
\hline \multirow[t]{3}{*}{ FUN } & Ave. (w/o 6) & 1,91 & 2,91 & 2,83 & 2,69 & 3,15 & 3,39 & 2,50 & 4,08 \\
\hline & StdDev (w/o 6) & 0,94 & 1,14 & 0,58 & 0,75 & 1,14 & 0,77 & 0,53 & 0,49 \\
\hline & \multicolumn{9}{|c|}{$\begin{array}{l}\text { Level (Average): } 2,93 \\
\text { Std. Dev: } 0,64\end{array}$} \\
\hline \multirow[t]{3}{*}{$\mathrm{OP}$} & Ave. (w/o 6) & 1,67 & 2,20 & 2,22 & 2,40 & 2,11 & 3,00 & 2,00 & 3,44 \\
\hline & StdDev (w/o 6) & 0,71 & 1,03 & 0,67 & 0,52 & 0,93 & 0,82 & 0,82 & 1,01 \\
\hline & \multicolumn{9}{|c|}{$\begin{array}{l}\text { Level (Average): } 2,38 \\
\text { Std. Dev: } 0,57\end{array}$} \\
\hline
\end{tabular}

of service perception) but in very specific cases. Nevertheless, in general, SLAs' use depends on the unit and its relationship with the DTI.

Benchmarking culture is present in the institution, although depending on the level at which it is used (strategic, functional, or operational); the perception of practical use and decision-making culture based on the findings is still sporadic.

Continuous improvement practices are mostly reported as emerging in the organization; however, they are related to managing IT projects and initiatives but not to the business operation.

Finally, the interviewees recognize that the IT function has contributed in a somewhat strong and very strong manner to achieve the organization's strategic objectives, thus inviting the IT branch to be more proactive and propositive.

\section{IT Governance}

Table 10 shows the evaluation given by the Group of Business (Business) respondents opposed to those of Information Technology (IT).

Table 9. IT competence and value - Total

\begin{tabular}{|c|c|c|c|c|c|c|c|c|}
\hline Question & $\mathbf{1}$ & $\mathbf{2}$ & $\mathbf{3}$ & $\mathbf{4}$ & $\mathbf{5}$ & $\mathbf{6}$ & $\mathbf{7}$ & $\mathbf{8}$ \\
\hline 1 & $28 \%$ & $6 \%$ & $2 \%$ & $0 \%$ & $11 \%$ & $4 \%$ & $15 \%$ & $2 \%$ \\
\hline 2 & $30 \%$ & $43 \%$ & $23 \%$ & $38 \%$ & $13 \%$ & $9 \%$ & $26 \%$ & $6 \%$ \\
\hline 3 & $15 \%$ & $15 \%$ & $49 \%$ & $32 \%$ & $32 \%$ & $28 \%$ & $32 \%$ & $15 \%$ \\
\hline 4 & $2 \%$ & $23 \%$ & $15 \%$ & $26 \%$ & $30 \%$ & $30 \%$ & $11 \%$ & $49 \%$ \\
\hline 5 & $4 \%$ & $6 \%$ & $4 \%$ & $2 \%$ & $13 \%$ & $15 \%$ & $4 \%$ & $26 \%$ \\
\hline 6 & $21 \%$ & $6 \%$ & $6 \%$ & $2 \%$ & $2 \%$ & $15 \%$ & $13 \%$ & $2 \%$ \\
\hline Ave. (w/o 6) & 2,05 & 2,80 & 2,96 & 2,91 & 3,22 & 3,50 & 2,59 & 3,91 \\
\hline StdDev (w/o 6) & 1,08 & 1,11 & 0,83 & 0,87 & 1,17 & 1,06 & 1,07 & 0,94 \\
\hline $\begin{array}{l}\text { Level (Average): 2,99 } \\
\text { Std. Dev: 0,57 }\end{array}$ & & & & &
\end{tabular}


Table 10. IT governance - Business vs. IT

\begin{tabular}{|c|c|c|c|c|c|c|c|c|}
\hline & Question & 1 & 2 & 3 & 4 & 5 & 6 & 7 \\
\hline \multirow[t]{3}{*}{ BUS } & Ave. (w/o 6) & 3,49 & 3,47 & 2,82 & 3,35 & 3,27 & 3,56 & 3,06 \\
\hline & StdDev (w/o 6) & 0,92 & 1,13 & 0,64 & 1,04 & 1,08 & 1,24 & 0,84 \\
\hline & \multicolumn{8}{|l|}{$\begin{array}{l}\text { Level (Average): 3,29 } \\
\text { Std. Dev: 0,27 }\end{array}$} \\
\hline \multirow[t]{3}{*}{ IT } & Ave. (w/o 6) & 3,25 & 3,00 & 2,78 & 2,80 & 3,18 & 2,64 & 2,67 \\
\hline & StdDev (w/o 6) & 0,75 & 0,60 & 0,44 & 0,79 & 0,41 & 1,63 & 0,99 \\
\hline & \multicolumn{8}{|l|}{$\begin{array}{l}\text { Level (Average): } 2,90 \\
\text { Std. Dev: } 0,25\end{array}$} \\
\hline
\end{tabular}

Table 11 shows the evaluation given by the group of respondents who are in Strategic positions (EST) opposed to those of the Functional (FUN) and Operational (OP) roles.

Finally, Table 12 shows the evaluation given by the entire population interviewed.

Regarding strategic business planning, it is perceived that, although it involves IT, the degree of involvement is the same as in any other organization's unit building the plan. Then, IT is requested to operationalize/materialize an specific strategy. Similarly, the IT strategic plan is perceived as being developed centrally for the organization and individually for each unit, which then involves IT for its implementation.

There is an almost unanimous feeling that the IT function is budgeted as a cost center. Some projects are considered as investments, specially those that imply more significant economic and institutional impact. Additionally, IT decisions are mainly based on ITs ability to increase productivity and efficiency.

Regarding prioritization of initiatives, a dichotomy is observed between a group that indicates that it is a reaction to a business or IT problem against those who indicate that the business and IT management determines it.

Table 11. IT governance - Strategic (EST) vs. Functional (FUN) vs. Operative (OP)

\begin{tabular}{|c|c|c|c|c|c|c|c|c|}
\hline & Question & 1 & 2 & 3 & 4 & 5 & 6 & 7 \\
\hline \multirow[t]{3}{*}{ EST } & Ave. (w/o 6) & 3,63 & 3,87 & 2,91 & 3,63 & 3,35 & 3,71 & 3,21 \\
\hline & StdDev (w/o 6) & 0,97 & 0,87 & 0,68 & 1,01 & 1,09 & 1,16 & 0,83 \\
\hline & \multicolumn{8}{|l|}{$\begin{array}{l}\text { Level (Average): } \mathbf{3 , 4 7} \\
\text { Std. Dev: } \mathbf{0 , 3 3}\end{array}$} \\
\hline \multirow[t]{3}{*}{ FUN } & Ave. (w/o 6) & 3,31 & 2,92 & 2,67 & 2,77 & 3,33 & 2,89 & 2,77 \\
\hline & StdDev (w/o 6) & 0,63 & 0,76 & 0,49 & 0,83 & 0,50 & 1,45 & 0,83 \\
\hline & \multicolumn{8}{|l|}{$\begin{array}{l}\text { Level (Average): } 2,95 \\
\text { Std. Dev: 0,27 }\end{array}$} \\
\hline \multirow[t]{3}{*}{ OP } & Ave. (w/o 6) & 3,10 & 2,70 & 2,71 & 2,71 & 2,88 & 2,80 & 2,50 \\
\hline & StdDev (w/o 6) & 0,88 & 1,16 & 0,49 & 0,76 & 0,84 & 1,69 & 0,85 \\
\hline & \multicolumn{8}{|l|}{$\begin{array}{l}\text { Level (Average): } 2,77 \\
\text { Std. Dev: 0,19 }\end{array}$} \\
\hline
\end{tabular}


Table 12. IT governance - Total

\begin{tabular}{|c|c|c|c|c|c|c|c|}
\hline Question & $\mathbf{1}$ & $\mathbf{2}$ & $\mathbf{3}$ & $\mathbf{4}$ & $\mathbf{5}$ & $\mathbf{6}$ & $\mathbf{7}$ \\
\hline 1 & $2 \%$ & $2 \%$ & $2 \%$ & $0 \%$ & $4 \%$ & $21 \%$ & $2 \%$ \\
\hline 2 & $9 \%$ & $19 \%$ & $19 \%$ & $30 \%$ & $11 \%$ & $0 \%$ & $32 \%$ \\
\hline 3 & $45 \%$ & $34 \%$ & $62 \%$ & $21 \%$ & $28 \%$ & $11 \%$ & $36 \%$ \\
\hline 4 & $34 \%$ & $28 \%$ & $6 \%$ & $34 \%$ & $34 \%$ & $47 \%$ & $28 \%$ \\
\hline 5 & $11 \%$ & $15 \%$ & $0 \%$ & $9 \%$ & $2 \%$ & $13 \%$ & $2 \%$ \\
\hline 6 & $0 \%$ & $2 \%$ & $11 \%$ & $6 \%$ & $21 \%$ & $9 \%$ & $0 \%$ \\
\hline $\begin{array}{l}\text { Ave. (w/o 6) } \\
\text { Level (Average): 3,19 }\end{array}$ & 3,43 & 3,35 & 2,81 & 3,23 & 3,24 & 3,33 & 2,96 \\
\hline Std. Dev: 0,22 & 0,88 & 1,04 & 0,59 & 1,01 & 0,93 & 1,39 & 0,88 \\
\hline
\end{tabular}

\section{Partnership / Association}

Table 13 shows the evaluation given by the Group of Business (Business) respondents, in contrast to those of Information Technology (IT).

Table 14 shows the evaluation given by the group of respondents who are in strategic positions (EST) opposed to those of the Functional (FUN) and Operational (OP) roles.

Finally, Table 15 shows the evaluation given by the entire population interviewed.

For a vast majority of interviewees (70\%), IT is considered as an enabler of future business activity, accompanied by positive comments regarding the effort made by the DTI to approach and publicize its services and products to all units of the organization. Regarding the IT role in strategic business planning, the responses are varied and show precisely that these perceptions depend somehow on the closeness of the DTI to the unit in question. However, the support from the DTI to IT initiatives of the other units is positively perceived.

The exchange of risks and rewards is the factor with the lowest evaluation of this dimension, which shows that much of the responsibility for IT initiatives is on the shoulders of the DTI. Simultaneously, some (nearby) units recognize that they are easing and sharing that burden with the business units. Regarding the relationship and trust between business and IT, it has the highest variability and surely requires more work by both parties. Finally, as an essential strength of the organization it is reported that initiatives often have business and IT promoters recognized by the interviewees.

Table 13. Partnership / Association - Business vs. IT

\begin{tabular}{|c|c|c|c|c|c|c|c|}
\hline & Question & 1 & 2 & 3 & 4 & 5 & 6 \\
\hline \multirow[t]{3}{*}{ BUS } & Ave. (w/o 6) & 3,29 & 3,57 & 2,86 & 3,03 & 2,94 & 3,06 \\
\hline & StdDev (w/o 6) & 0,91 & 1,12 & 1,06 & 1,12 & 1,33 & 0,84 \\
\hline & \multicolumn{7}{|l|}{$\begin{array}{l}\text { Level (Average): } 3,13 \\
\text { Std. Dev: } 0,26\end{array}$} \\
\hline \multirow[t]{3}{*}{ IT } & Ave. (w/o 6) & 2,92 & 3,09 & 2,17 & 2,42 & 2,83 & 3,00 \\
\hline & StdDev (w/o 6) & 0,29 & 1,22 & 0,84 & 0,67 & 1,03 & 0,74 \\
\hline & \multicolumn{7}{|l|}{$\begin{array}{l}\text { Level (Average): } 2,74 \\
\text { Std. Dev: } 0,36\end{array}$} \\
\hline
\end{tabular}


Table 14. Partnership /Association - Strategic (EST) vs. Functional (FUN) vs. Operative (OP)

\begin{tabular}{|c|c|c|c|c|c|c|c|}
\hline & Question & 1 & 2 & 3 & 4 & 5 & 6 \\
\hline \multirow[t]{3}{*}{ EST } & Ave. (w/o 6) & 3,54 & 3,79 & 3,00 & 3,09 & 3,17 & 3,21 \\
\hline & StdDev (w/o 6) & 0,88 & 1,06 & 1,07 & 1,11 & 1,31 & 0,93 \\
\hline & \multicolumn{7}{|l|}{$\begin{array}{l}\text { Level (Average): } \mathbf{3 , 3 0} \\
\text { Std. Dev: } 0,30\end{array}$} \\
\hline \multirow[t]{3}{*}{ FUN } & Ave. (w/o 6) & 2,85 & 3,39 & 2,46 & 2,77 & 2,77 & 3,00 \\
\hline & StdDev (w/o 6) & 0,38 & 1,19 & 0,69 & 1,17 & 1,09 & 0,58 \\
\hline & \multicolumn{7}{|l|}{$\begin{array}{l}\text { Level (Average): } 2,87 \\
\text { Std. Dev: } 0,31\end{array}$} \\
\hline \multirow[t]{3}{*}{$\mathrm{OP}$} & Ave. (w/o 6) & 2,78 & 2,78 & 1,88 & 2,56 & 2,40 & 2,70 \\
\hline & StdDev (w/o 6) & 0,67 & 1,20 & 0,84 & 0,53 & 1,08 & 0,68 \\
\hline & \multicolumn{7}{|l|}{$\begin{array}{l}\text { Level (Average): } 2,51 \\
\text { Std. Dev: } 0,35\end{array}$} \\
\hline
\end{tabular}

\section{Scope and Infrastructure of IT}

Table 16 shows the evaluation given by the respondents of the Group of Business (BUS), in contrast with those of Information Technology (IT).

Table 17 shows the evaluation given by the group of respondents who are in Strategic positions (EST) opposed to those of the Functional (FUN) and Operational (OP) roles.

Finally, Table 18 shows the evaluation given by the entire population interviewed.

Concerning the scope of IT systems, 55\% of respondents perceive it as an enabler of business processes, i.e., IT supports changes in the business process, which is true in terms of processes closely related to academic and administrative management. Regarding the use of IT standards, they are only noted as existent in the organization's IT and management areas. Apropos of the scope of the architectural integration and the degree of integration of its components, it is perceived that there is integration at the level of functional units and that the relationship with customers and external suppliers is emerging in specific cases (e.g., government agencies).

Table 15. Partnership / Association - Total

\begin{tabular}{|c|c|c|c|c|c|c|}
\hline Question & $\mathbf{1}$ & $\mathbf{2}$ & $\mathbf{3}$ & $\mathbf{4}$ & $\mathbf{5}$ & $\mathbf{6}$ \\
\hline 1 & $2 \%$ & $0 \%$ & $11 \%$ & $4 \%$ & $15 \%$ & $4 \%$ \\
\hline 2 & $6 \%$ & $30 \%$ & $30 \%$ & $38 \%$ & $21 \%$ & $11 \%$ \\
\hline 3 & $70 \%$ & $15 \%$ & $30 \%$ & $23 \%$ & $36 \%$ & $68 \%$ \\
\hline 4 & $9 \%$ & $32 \%$ & $13 \%$ & $21 \%$ & $13 \%$ & $11 \%$ \\
\hline 5 & $11 \%$ & $21 \%$ & $4 \%$ & $6 \%$ & $15 \%$ & $6 \%$ \\
\hline 6 & $2 \%$ & $2 \%$ & $13 \%$ & $6 \%$ & $0 \%$ & $0 \%$ \\
\hline Ave. (w/o 6) &, 20 & 3,46 & 2,66 & 2,86 & 2,92 & 3,04 \\
\hline $\begin{array}{l}\text { Level (Average): 3,02 } \\
\text { StdDev: 0,28 }\end{array}$ & 0,81 & 1,15 & 1,04 & 1,05 & 1,25 & 0,81 \\
\hline
\end{tabular}


Table 16. Scope and infrastructure of IT - Business vs. IT

\begin{tabular}{|c|c|c|c|c|c|c|}
\hline & Question & 1 & 2 & 3 & 4 & 5 \\
\hline \multirow[t]{3}{*}{ BUS } & Ave. (w/o 6) & 3,25 & 3,46 & 2,88 & 2,53 & 3,31 \\
\hline & StdDev (w/o 6) & 0,76 & 1,06 & 0,91 & 1,11 & 0,86 \\
\hline & \multicolumn{6}{|l|}{$\begin{array}{l}\text { Level (Average): } 3,09 \\
\text { Std. Dev: 0,38 }\end{array}$} \\
\hline \multirow[t]{3}{*}{ IT } & Ave. (w/o 6) & 2,83 & 3,25 & 3,00 & 2,36 & 2,75 \\
\hline & StdDev (w/o 6) & 0,58 & 0,87 & 1,00 & 1,29 & 1,14 \\
\hline & \multicolumn{6}{|l|}{$\begin{array}{l}\text { Level (Average): } 2,84 \\
\text { Std. Dev: } 0,33\end{array}$} \\
\hline
\end{tabular}

Table 17. Scope and infrastructure of IT - Strategic (EST) vs. Functional (FUN) vs. Operative (OP)

\begin{tabular}{|c|c|c|c|c|c|c|}
\hline & Question & 1 & 2 & 3 & 4 & 5 \\
\hline \multirow[t]{3}{*}{ EST } & Ave. (w/o 6) & 3,30 & 3,58 & 3,04 & 2,43 & 3,39 \\
\hline & StdDev (w/o 6) & 0,70 & 1,07 & 0,88 & 1,08 & 0,78 \\
\hline & \multicolumn{6}{|l|}{$\begin{array}{l}\text { Level (Average): } \mathbf{3 , 1 5} \\
\text { Std. Dev: } 0,45\end{array}$} \\
\hline \multirow[t]{3}{*}{ FUN } & Ave. (w/o 6) & 3,15 & 3,30 & 3,09 & 2,77 & 3,39 \\
\hline & StdDev (w/o 6) & 0,80 & 0,82 & 0,70 & 1,17 & 1,04 \\
\hline & \multicolumn{6}{|l|}{$\begin{array}{l}\text { Level (Average): 3,14 } \\
\text { Std. Dev: 0,24 }\end{array}$} \\
\hline \multirow[t]{3}{*}{$\mathrm{OP}$} & Ave. (w/o 6) & 2,67 & 3,00 & 2,50 & 2,38 & 2,33 \\
\hline & StdDev (w/o 6) & 0,50 & 0,93 & 1,18 & 1,41 & 0,87 \\
\hline & \multicolumn{6}{|l|}{$\begin{array}{l}\text { Level (Average): } \mathbf{2 , 5 8} \\
\text { Std. Dev: } 0,27\end{array}$} \\
\hline
\end{tabular}

Table 18. Scope and infrastructure of IT - Total

\begin{tabular}{|c|c|c|c|c|c|}
\hline Question & $\mathbf{1}$ & $\mathbf{2}$ & $\mathbf{3}$ & $\mathbf{4}$ & $\mathbf{5}$ \\
\hline 1 & $0 \%$ & $0 \%$ & $9 \%$ & $21 \%$ & $2 \%$ \\
\hline 2 & $15 \%$ & $19 \%$ & $17 \%$ & $26 \%$ & $26 \%$ \\
\hline 3 & $55 \%$ & $17 \%$ & $40 \%$ & $17 \%$ & $26 \%$ \\
\hline 4 & $19 \%$ & $32 \%$ & $26 \%$ & $23 \%$ & $36 \%$ \\
\hline 5 & $4 \%$ & $9 \%$ & $0 \%$ & $0 \%$ & $4 \%$ \\
\hline 6 & $6 \%$ & $23 \%$ & $9 \%$ & $13 \%$ & $6 \%$ \\
\hline Ave. (w/o 6) & 3,14 & 3,39 & 2,91 & 2,49 & 3,16 \\
\hline StdDev (w/o 6) & 0,73 & 0,99 & 0,92 & 1,14 & 0,96 \\
\hline $\begin{array}{l}\text { Level (Average): 3,02 } \\
\text { Std. Dev: 0,34 }\end{array}$ & & & & \\
\hline
\end{tabular}


Table 19. IT skills - Business vs. IT

\begin{tabular}{|c|c|c|c|c|c|c|c|c|}
\hline & Question & 1 & 2 & 3 & 4 & 5 & 6 & 7 \\
\hline \multirow[t]{3}{*}{ BUS } & Ave. (w/o 6) & 3,03 & 2,70 & 3,00 & 2,23 & 2,52 & 2,91 & 2,68 \\
\hline & StdDev (w/o 6) & 1,12 & 0,95 & 1,05 & 1,22 & 1,02 & 1,00 & 0,67 \\
\hline & \multicolumn{8}{|l|}{$\begin{array}{l}\text { Level (Average): } 2,73 \\
\text { Std. Dev: } 0,29\end{array}$} \\
\hline \multirow[t]{3}{*}{ IT } & Ave. (w/o 6) & 2,08 & 2,67 & 2,25 & 1,58 & 2,00 & 3,00 & 1,92 \\
\hline & StdDev (w/o 6) & 0,52 & 0,89 & 1,06 & 0,52 & 1,10 & 1,04 & 0,90 \\
\hline & \multicolumn{8}{|l|}{$\begin{array}{l}\text { Level (Average): } 2,21 \\
\text { Std. Dev: } 0,48\end{array}$} \\
\hline
\end{tabular}

Additionally, the disruption caused by business and IT changes are perceived as highly varied, so there is no clear conclusion. Furthermore, the average of this attribute is the worst in the dimension $(2,48)$, which suggests the need to perform an in-depth review of this factor. Determining whether it is due to ignorance or bad experiences in implementing IT initiatives can shed light on a way to improve the processes of organizational change management.

Finally, the attribute referring to how IT infrastructure is perceived shows a tendency to emerge as a resource to allow a rapid response to market changes and make IT a significant ally, especially for the administrative and academic vice rectories.

\section{IT Skills}

Table 19 shows the evaluation given by the respondents of the Group of Business (BUS), in contrast to those of Information Technology (IT).

Table 20 shows the evaluation given by the group of respondents who are in Strategic positions (EST) in contrast with those of the Functional (FUN) and Operational (OP) roles.

Finally, Table 21 shows the evaluation given by the entire population interviewed.

This dimension is the one with the lowest evaluations and the highest standard deviation. Regarding the attribute that enquires about the promotion of entrepreneurship, responses were

Table 20. IT skills - Strategic (EST) vs. Functional (FUN) vs. Operative (OP)

\begin{tabular}{|c|c|c|c|c|c|c|c|c|}
\hline & Question & 1 & 2 & 3 & 4 & 5 & 6 & 7 \\
\hline \multirow[t]{3}{*}{ EST } & Ave. (w/o 6) & 3,32 & 2,95 & 3,05 & 2,25 & 2,57 & 3,23 & 2,80 \\
\hline & StdDev (w/o 6) & 1,00 & 0,87 & 1,05 & 1,07 & 1,03 & 0,92 & 0,68 \\
\hline & \multicolumn{8}{|l|}{$\begin{array}{l}\text { Level (Average): } \mathbf{2 , 8 8} \\
\text { Std. Dev: } 0,38\end{array}$} \\
\hline \multirow[t]{3}{*}{ FUN } & Ave. (w/o 6) & 2,39 & 2,54 & 2,54 & 2,15 & 2,00 & 2,85 & 2,38 \\
\hline & StdDev (w/o 6) & 0,87 & 0,88 & 0,88 & 1,35 & 0,78 & 0,99 & 0,74 \\
\hline & \multicolumn{8}{|l|}{$\begin{array}{l}\text { Level (Average): } 2,41 \\
\text { Std. Dev: 0,28 }\end{array}$} \\
\hline \multirow[t]{3}{*}{$\mathrm{OP}$} & Ave. (w/o 6) & 2,00 & 2,33 & 2,50 & 1,50 & 2,38 & 2,40 & 1,78 \\
\hline & StdDev (w/o 6) & 0,82 & 1,00 & 1,35 & 0,53 & 1,41 & 0,97 & 0,83 \\
\hline & \multicolumn{8}{|l|}{$\begin{array}{l}\text { Level (Average): } 2,13 \\
\text { Std. Dev: } 0,38\end{array}$} \\
\hline
\end{tabular}


Table 21. IT skills - Total

\begin{tabular}{|c|c|c|c|c|c|c|c|}
\hline Question & $\mathbf{1}$ & $\mathbf{2}$ & $\mathbf{3}$ & $\mathbf{4}$ & $\mathbf{5}$ & $\mathbf{6}$ & $\mathbf{7}$ \\
\hline 1 & $6 \%$ & $9 \%$ & $11 \%$ & $28 \%$ & $11 \%$ & $9 \%$ & $13 \%$ \\
\hline 2 & $43 \%$ & $30 \%$ & $32 \%$ & $47 \%$ & $51 \%$ & $21 \%$ & $17 \%$ \\
\hline 3 & $15 \%$ & $32 \%$ & $19 \%$ & $4 \%$ & $11 \%$ & $34 \%$ & $34 \%$ \\
\hline 4 & $26 \%$ & $19 \%$ & $30 \%$ & $4 \%$ & $6 \%$ & $28 \%$ & $2 \%$ \\
\hline 5 & $4 \%$ & $0 \%$ & $2 \%$ & $6 \%$ & $6 \%$ & $2 \%$ & $0 \%$ \\
\hline 6 & $6 \%$ & $11 \%$ & $6 \%$ & $11 \%$ & $15 \%$ & $6 \%$ & $34 \%$ \\
\hline $\begin{array}{l}\text { Ave. (w/o 6) } \\
\text { Level (Average): 2,57 }\end{array}$ & 2,77 & 2,69 & 2,80 & 2,05 & 2,38 & 2,93 & 2,39 \\
\hline Std. Dev: 0,31 & 1,08 & 0,92 & 1,09 & 1,10 & 1,06 & 1,00 & 0,84 \\
\hline
\end{tabular}

varied and it could be said that they were opposed. At the level of the functional unit, the majority of respondents indicated that they are moderately encouraged (43\%). On the contrary, especially for the people in strategic roles, it is strongly encouraged at the functional and corporate units $(26 \%)$.

The attribute that indicates how IT decisions are made shows that for strategic levels, it is perceived that decisions belong to the top corporate management with shared influence emerging from IT management. For the remaining people, the influence depends on how the interviewee is in the decision-making hierarchy. However, it is also clear to the interviewees that the margin of action of IT is reduced because it is sheltered under the administrative vice-rectory.

A high standard deviation is first noticed for the attribute that measures the organization's readiness for change. Likewise, the responses depend on the position of the interviewee in the functional organization. For instance, the interviewees of the strategic level, for whom change programs are defined at the corporate level, have a positive perception-however, lower in the hierarchy, this perception changes.

Concerning the opportunities for rotation between business and IT personnel, it is clear that this turnover hardly ever occurs and has been generally from business to IT and not the other way around. Moreover, the attribute that measures employees' opportunities to learn and support services outside the functional unit indicates that these opportunities exist between academic and management areas and IT but are still scarce. Regarding the interpersonal interaction IT/business, perceptions are varied but positive, in the sense that for some people, trust is emerging, and for others, it has already been achieved.

Finally, regarding the IT organization's ability to attract and retain the best business professionals, although the consensus tends to focus on technical and business experience, there was a high level of abstention, i.e., respondents mostly chose the "does not know/does not apply" option.

\section{DISCUSSION}

As a result of the complete application of the Luftman instrument, we found that the organization's overall maturity level is approximately 3 (2,98). For Luftman (Brocke \& Rosemann (eds.), 2015), the level 3 organization has “...established focused processes. IT has become more integrated enterprise-wide. Understanding of the business and IT is emerging at senior and mid-level. Service level agreements (SLAs) have begun to be used and acted. Strategic planning tends to be done at the business unit level, although some inter-organizational planning has already started. The business increasingly views IT as an asset, but project prioritization still usually responds to the loudest voice. 
Table 22. Data comparison - Case organization vs. (Brocke \& Rosemann (eds.), 2015) and (J. Luftman et al., 2017)

\begin{tabular}{|l|c|c|c|c|c|c|}
\hline \multicolumn{1}{|c|}{ Dimension } & $\begin{array}{c}\text { CASE } \\
\text { ORGANIZATION }\end{array}$ & $\begin{array}{c}\text { STD. } \\
\text { DEV }\end{array}$ & $\begin{array}{c}\text { LUFTMAN } \\
\mathbf{2 0 1 7}\end{array}$ & $\begin{array}{c}\text { LUFTMAN } \\
\text { STD. DEV } \\
\mathbf{2 0 1 7}\end{array}$ & $\begin{array}{c}\text { EDUCATION } \\
\text { LUFTMAN } \\
\mathbf{2 0 1 5}\end{array}$ & $\begin{array}{c}\text { LATIN } \\
\text { AMERICA } \\
\mathbf{2 0 1 5}\end{array}$ \\
\hline COMMUNICATIONS & 3,07 & 0,34 & 3,00 & 0,72 & 2,66 & 3,17 \\
\hline $\begin{array}{l}\text { IT COMPETENCE } \\
\text { AND VALUE }\end{array}$ & 2,99 & 0,57 & 2,94 & 0,84 & 2,48 & 2,94 \\
\hline IT GOVERNANCE & 3,19 & 0,22 & 3,11 & 0,77 & 2,83 & 3,03 \\
\hline PARTNERSHIP & 3,02 & 0,28 & 3,08 & 0,85 & 2,53 & 3,16 \\
\hline IT SCOPE & 3,02 & 0,34 & 3,12 & 0,81 & 2,72 & 3,27 \\
\hline IT SKILLS & 2,57 & 0,31 & 2,92 & 0,82 & 2,56 & 3,00 \\
\hline
\end{tabular}

Formal IT steering committees emerge and meet regularly. IT spending tends to be controlled by budgets, and IT is still seen as a cost center. But awareness of IT's investment potential is emerging. The business is more tolerant of risk and is willing to share some risk with IT. At the functional level, the business sponsors IT projects, and career crossovers between business and IT areas occur. Both business and technical skills are important to business and IT managers. Technology standards and architecture have emerged at both the enterprise level and with key external partners..."

It is also essential to observe the different perceptions according to the dimensions of comparison initially proposed by Luftman when evaluating the results, i.e., business vs. IT. It is important to notice that the number of business interviews is larger and less homogeneous than IT. This also shows a more positive view of aspects of alignment among business people than the IT staff.

When comparing strategic levels with functional and operational personnel, the staff at strategic levels has a more positive vision regarding their counterparts. However, it can be understood that these roles are closer to IT decisions and initiatives in the organization, either because they are informed or because they participate as users, promoters, or as members of the different organization committees.

Another finding is that the relationship of trust, communications, and knowledge exchange between business and IT requires attention. The administrative and academic vice rectories are the main focus due to their economic/missional dependence on them, and their relation with IT is in good standing. However, other units require attention regarding their relationship with IT, where IT is seen in a support/provider role and not in a strategic one. In this regard, it is worth mentioning that the organization is aware of this issue and is willing to work on it to improve the current situation. Likewise, it is essential to work on the IT Personal Skills factor, which is the dimension with the lowest score.

Finally, IT's role should be questioned concerning the definition of the business strategy and its place in the organizational hierarchy. Both issues require transforming the IT role from a service provider to an enabler or even the driver of the organization's strategy. The enabler role is perceived by many interviewees at the strategic level but is not operationally perceived when collating the other evaluated attributes together.

\section{Comparison with Other Organizations}

This section compares our results with the results reported by Luftman at different times (2015 and 2017).

The data that details the comparison by geographic location and type of industry was reported by Luftman in (Brocke \& Rosemann (eds.), 2015). At that time, Luftman reported that the instrument had been applied in more than 2100 interviews that covered 362 companies between the years 2000 and 2015. Of those 362 companies, 11 are within the Education sector, and 44 are Latin American. 
Table 22 presents the comparison of the evaluation of dimensions reported for our case and its standard deviation, the averages reported by Luftman in 2017 and their standard deviation, the values reported by Luftman in 2015 for the education sector, and finally the values of those organizations located geographically in Latin America.

In 2017, (J. Luftman et al., 2017) reported that the instrument had been applied to 3029 people from 392 organizations; however, they provided no detailed information per type of organization or geographic location. As shown in Table 22, compared to the averages of the 395 organizations reported by Luftman in 2017, the organization has a similar behavior, with a significant difference in the dimension related to IT talent skills (as discussed in section IT Skills).

\section{On the Use of Luftman's Instrument}

Apart from the BITA assessment itself, we intended to give some insights into Luftman's instrument application. To achieve this, we used the framework proposed by Daoudi and Nurcan (Daoudi \& Nurcan, n.d.) that provides guidelines about how to evaluate and organize a business process. In this context, the process analyzed is Luftman's instrument/process.

The framework proposes four aspects of analysis:

1. The way of thinking verbalizes the method's assumptions and viewpoints on problem domains, solutions, and modelers.

2. The way of working structures how the processes are designed. It defines the possible tasks to be performed as part of the design and development process. It provides heuristics on how these tasks should be performed.

3. The way of modeling provides information on the modeling concepts, on their properties and their relationships. It gives a formalism and notation to express process models.

4. The way of supporting refers to the tools supporting the design and development of the process models and offers a repository to store and exploit it.

According to Daoudi's proposal, our main conclusions regarding Luftman's instrument are as follows:

1. Way of thinking: The method is not under discussion, but the way it is used and how to get the most of it.

2. Way of working: Our approach applies the comparison of both Business and IT groups. Due to the number of interviews, we were able to segment the interviewees and analyze their responses by their organizational hierarchy position, i.e., strategic, operational, and functional. This segmented analysis provides another point of view of the organization vertically, thus enriching the study results.

3. Way of modeling: We found that even though the alignment is a concept that most decisionmaking people understand, concepts of BITA were not necessarily understood. That is why we do not trust reports where respondents spent about an hour to fill a large questionnaire without supervision and feedback. We believe that the instrument application requires performing an interview, where the interviewer can explain and contextualize the concepts behind the questionnaire. The interviewee can explain and argue their answers and perceptions.

4. Way of supporting: To better support the process, it is useful to capture the quantitative data from the questionnaires and record and analyze the interviewees' responses and arguments. In this sense, it could also be useful that more researchers publish and share their results, especially to analyze and identify trends in specific sectors or geographical areas. The use of spreadsheets to tabulate the data and audio processing apps is key to organize and analyze the information. 
In our case, one person transcribed the interviews, but it could be useful to record the interview and use some automatic transcription services.

\section{CONCLUSIONS AND FUTURE WORK}

In this paper, we first presented a brief description, history, and definitions of BITA, particularly the instrument proposed by Luftman, to analyze it. Then, we characterized an educational institution where the instrument was applied. Afterward, we reported the results of a BITA assessment performed within the institution, as previously mentioned.

Our analysis of the instrument application highlights a couple of drawbacks in most of the previous studies that used the Luftman instrument. First, the authors of those studies do not describe in detail the process of applying the instrument. Second, they report that very few analyzed organizations answered the questionnaires when applying the instrument. Additionally, there were no interviews in most cases, as the respondents just filled the instrument forms. These are real problems that might threaten the validity of any study. After applying the instrument, this was even more evident since the questionnaire has a considerable length (almost forty questions), and its technical language is not necessarily well-understood by everybody. For instance, we found that IT people understand the instrument language and goal, in contrast to personnel in business areas and at the operative and functional levels who sometimes think that the prominent role of the DTI is to fix computers, printers, email, and office software configuration. This can be seen quantitatively when comparing the operative and functional levels' resulting perceptions, where almost every dimension was scored lower than the strategic levels (See Table 5, Table 8, Table 11, Table 14, Table 17, and Table 20) .

Moreover, we found that the interviewers' role is essential when applying the instrument. Among the perceived advantages are the possibility of explaining the purpose of the study to the interviewees, describing the structure of the instrument, clarifying the questions in the questionnaire, and encouraging each of the interviewees to explain the rationale behind their answers and perceptions. In conclusion, the interview format allows the researcher to guide the study towards the pursued goal.

For future work, we plan to analyze business and IT goals using Goal-oriented Requirements Engineering (GORE) in business/IT initiatives and their impact on such goals. This study was used to introduce the problem and different ways to measure, analyze, and understand alignment in a real-life setting. 


\section{REFERENCES}

Baker, J., \& Singh, H. (2019). The roots of misalignment: Insights on strategy implementation from a system dynamics perspective. The Journal of Strategic Information Systems, 28(4), 101576. Advance online publication. doi:10.1016/j.jsis.2019.101576

Beffers, R., \& de Waal, B. (2018). Enhancing the Strategic Alignment Model: The Contribution of BiSL. Proceedings of the European Conference on Management, Leadership \& Governance, 18.

Berberat, S., \& Baudet, C. (2019). Assessing a Business Software Application using Strategic IT Alignment Factors: A New Way for IS Evaluation? ICEB 2019 Proceedings. https://aisel.aisnet.org/iceb2019/19

BiSL. (n.d.). DIDFOUNDATION. Retrieved December 7, 2020, from https://www.didfoundation.com/bisl/

Brocke, J. vom, \& Rosemann, M. (Eds.). (2015). Handbook on Business Process Management 2: Strategic Alignment, Governance, People and Culture (2nd ed.). Springer-Verlag Berlin Heidelberg. http://gen.lib.rus.ec/ book/index.php?md5=73eb085953b98d12df94b60ea17ec07a

Buchalcevova, A., \& Pour, J. (2018). Model of Business-IT Alignment. FAIMA Business \& Management Journal, 6(1), 14.

Calder, A. (2019). ISO/IEC 38500: A pocket guide ( $2^{\text {nd }}$ ed.). http://gen.lib.rus.ec/book/index.php?md5=ADD3 05C8BF45F9AD88B5871F5987056E

Chan, Y. E., \& Reich, B. H. (2007). IT alignment: What have we learned? Journal of Information Technology, 22(4), 297-315. doi:10.1057/palgrave.jit.2000109

Daoudi, F., \& Nurcan, S. (n.d.). A framework to evaluate methods' capacity to design flexible business processes. ResearchGate. Retrieved November 7, 2019, from https://www.researchgate.net/publication/264842746_A_ framework_to_evaluate_methods'_capacity_to_design_flexible_business_processes

Darii, H., Laval, J., Botta-Genoulaz, V., \& Goepp, V. (2020). Measurement of the Business/IT Alignment of Information Systems. Academic Press.

De Haes, S., \& Van Grembergen, W. (2009). An Exploratory Study into IT Governance Implementations and its Impact on Business/IT Alignment. Information Systems Management, 26(2), 123-137. doi:10.1080/10580530902794786

El-Mekawy, M., Rusu, L., \& Perjons, E. (2015). An evaluation framework for comparing business-IT alignment models: A tool for supporting collaborative learning in organizations. Computers in Human Behavior, 51(Part B), 1229-1247. 10.1016/j.chb.2014.12.016

Elhari, K., \& Bounabat, B. (2011). Platform for assessing strategic alignment using enterprise architecture: Application to e-government process assessment. ArXiv Preprint ArXiv:1104.1132.

Estructura Organizacional, Pontificia Universidad Javeriana. (n.d.). Retrieved March 16, 2018, from https:// www.javeriana.edu.co/institucional/estructura-organizacional

Fernández Martínez, A., \& Llorens Largo, F. (2011). Gobierno de las TI para universidades. CRUE TIC.

Gampfer, F., Jürgens, A., Müller, M., \& Buchkremer, R. (2018). Past, current and future trends in enterprise architecture-A view beyond the horizon. Computers in Industry, 100, 70-84. doi:10.1016/j.compind.2018.03.006

Goni, F. A., Chofreh, A. G., Mukhtar, M., Sahran, S., Shukor, S. A., \& Klemeš, J. J. (2017). Strategic alignment between sustainability and information systems: A case analysis in Malaysian public Higher Education Institutions. Journal of Cleaner Production, 168(Supplement C), 263-270. doi:10.1016/j.jclepro.2017.09.021

Gti4u. (n.d.). Retrieved October 15, 2018, from http://www.gti4u.es/

Gutierrez, A., Mylonadis, C., Orozco, J., \& Serrano, A. (2008). Business-IS Alignment: Assessment Process to Align IT Projects With Business Strategy. AMCIS 2008 Proceedings. https://aisel.aisnet.org/amcis2008/290

Gutierrez, A., Orozco, J., \& Serrano, A. (2009). Factors affecting IT and business alignment: A comparative study in SMEs and large organisations. Journal of Enterprise Information Management, 22(1/2), 197-211. doi:10.1108/17410390910932830 
Haghighi Rad, F., \& Rowzan, S. M. (2018). Designing a hybrid system dynamic model for analyzing the impact of strategic alignment on project portfolio selection. Simulation Modelling Practice and Theory, 89, 175-194. doi:10.1016/j.simpat.2018.10.001

Henderson, J. C., \& Venkatraman, N. (1993). Strategic alignment: Leveraging information technology for transforming organizations. IBM Systems Journal, 1(1), 4. doi:10.1147/sj.382.0472

Héroux, S., \& Fortin, A. (2018). The moderating role of IT-business alignment in the relationship between IT governance, IT competence, and innovation. Information Systems Management, 35(2), 98-123. doi:10.1080/1 0580530.2018 .1440729

Huang, C. D., \& Hu, Q. (2007). Achieving IT-Business Strategic Alignment via Enterprise-Wide Implementation of Balanced Scorecards. Information Systems Management, 24(2), 173-184. doi:10.1080/10580530701239314

Ilmudeen, A., Bao, Y., \& Alharbi, I. M. (2019). How does business-IT strategic alignment dimension impact on organizational performance measures: Conjecture and empirical analysis. Journal of Enterprise Information Management, 32(3), 457-476. doi:10.1108/JEIM-09-2018-0197

Índice: Boletín Estadístico 2016. (n.d.). Retrieved October 31, 2018, from https://www.javeriana.edu.co/ bolplaneacion2017/index.php

ISACA. (2018). COBIT 2019 Framework: Governance and Management Objectives. Isaca. http://gen.lib.rus. ec/book/index.php?md5=55AFCE9E31A08E5DD0E799D37BE98092

Kearns, G. S., \& Sabherwal, R. (2006). Strategic Alignment Between Business and Information Technology: A Knowledge-Based View of Behaviors, Outcome, and Consequences. Journal of Management Information Systems, 23(3), 129-162. doi:10.2753/MIS0742-1222230306

Luftman, J. (2000). Assessing Business-IT Alignment Maturity. Communications of the Association for Information Systems, 4(1). https://aisel.aisnet.org/cais/vol4/iss1/14

Luftman, J., Lyytinen, K., \& Zvi, T. (2017). Enhancing the measurement of information technology (IT) business alignment and its influence on company performance. Journal of Information Technology, 32(1), 26-46. doi:10.1057/jit.2015.23

Luftman, J. N. (1996). Competing in the Information Age: Strategic Alignment in Practice (1st ed.). Oxford University Press, Inc.

Luftman, J. N. (2003). Competing in the Information Age: Align in the Sand (2nd ed.). Oxford University Press. doi:10.1093/0195159535.001.0001

Majstorović, M. N. (2016). Business and It Alignment. Poravnanje Poslovanja I Informacione Tehnologije, 64(2), 496-512. doi:10.5937/vojtehg64-9263

Oehlhorn, C. E., Maier, C., Laumer, S., \& Weitzel, T. (2020). Human resource management and its impact on strategic business-IT alignment: A literature review and avenues for future research. The Journal of Strategic Information Systems, 29(4), 101641. Advance online publication. doi:10.1016/j.jsis.2020.101641

Park, J., Lee, J., Lee, O. D., \& Koo, Y. (2017). Alignment Between Internal and External IT Governance and Its Effects on Distinctive Firm Performance: An Extended Resource-Based View. IEEE Transactions on Engineering Management, 64(3), 351-364. doi:10.1109/TEM.2017.2678485

Putz, R. B. Z., Rasoto, V. I., \& Ishikawa, E. (2017). Brazilian federal universities information technology governance: An analysys of the strategic alignment dimension. 2017 12th Iberian Conference on Information Systems and Technologies (CISTI), 1-7. doi:10.23919/CISTI.2017.7975955

Reich, B. H., \& Benbasat, I. (1996). Measuring the Linkage Between Business and Information Technology Objectives. Management Information Systems Quarterly, 20(1), 55-81. doi:10.2307/249542

Reich, B. H., \& Benbasat, I. (2000). Factors That Influence the Social Dimension of Alignment Between Business and Information Technology Objectives. Management Information Systems Quarterly, 24(1), 81-113. doi: $10.2307 / 3250980$

Street, C. T., Gallupe, R., \& Baker, J. (2017). Strategic Alignment in SMEs: Strengthening Theoretical Foundations. Commun. Assoc. Inf. Syst. 10.17705/1CAIS.04020 
T.S., L. (2017). Evaluation of Business and it strategic alignment maturity in Russian companies. Вестник Южно-Уральского Государственного Университета. Серия: Компьютерные Технологии, Управление, Радиоэлектроника, 17(2). https://cyberleninka.ru/article/n/evaluation-of-business-and-it-strategic-alignmentmaturity-in-russian-companies-1

Wautelet, Y. (2019). A model-driven IT governance process based on the strategic impact evaluation of services. Journal of Systems and Software, 149, 462-475. doi:10.1016/j.jss.2018.12.024

Zhang, M., Chen, H., \& Luo, A. (2018). A Systematic Review of Business-IT Alignment Research With Enterprise Architecture. IEEE Access: Practical Innovations, Open Solutions, 6, 18933-18944. doi:10.1109/ ACCESS.2018.2819185

Miguel Torres-Moreno is a Systems Engineer from the Universidad Nacional de Colombia, MSc in Computer Science from Mississippi State University, Doctorate Candidate for the Ph.D. in Systems and Computer Engineering from Universidad Nacional de Colombia. In addition, he works as an associate professor at the Faculty of Engineering at Pontificia Universidad Javeriana, Bogotá, Colombia. His areas of interest are Strategic alignment, Software Engineering, with a focus on Requirements Engineering, testing, quality, Component-Based Development, and Intelligent Systems.

Jairo Aponte is an Associate Professor in the Department of Computer and Industrial Engineering at Universidad Nacional de Colombia. His current research interests are in software engineering, with a focus on agile software development, program comprehension, and software evolution. 